\title{
Black and Hispanic Representation in Policing: \\ Organizational and Local Labor Market Context
}

\author{
by \\ Moriah W. Willow \\ Philip N. Cohen \\ University of Maryland, College Park
}

January 2017

Paper submitted to the 2017 meetings of the American Sociological Association

\begin{abstract}
Recent events, such as highly visible police shootings, have highlighted the underrepresentation of racial minorities in U.S. policing. Past research has found a strong relationship between the local concentrations of a racial minority group and increased representation among police, as well as evidence of the disparate treatment of Blacks and Hispanics by White police officers. Using confidential, establishment-level public employment data on police departments from the Equal Employment Opportunity Commission, linked to Census local labor market data, we examine how department size and local demographic dynamics are associated with Black/Hispanic underrepresentation in policing. We find that police departments in labor markets with larger Black and Hispanic populations, and those with a greater number of officers on their force, are more likely to report underrepresentation of Black and Hispanic officers relative to the labor market. However, the effect of local population composition is reduced for bigger departments, suggesting a positive effect of organization visibility on minority police integration. In addition, the presence of Blacks and Hispanics in top leadership positions is positively associated with proportional representation, suggesting that minorities in leadership positions may have a beneficial impact on Black and Hispanic officer hiring.
\end{abstract}




\section{Black and Hispanic Representation in Policing: \\ Organizational and Local Labor Market Context}

\section{Introduction}

Recent events have highlighted the issue of Black underrepresentation within U.S. police and other law enforcement agencies. Following the fatal shooting of Michael Brown, an unarmed Black teenager, by a White police officer in Ferguson, Missouri, and the subsequent tumult, many chose to spotlight the racial mismatch between the virtually all White police department and the predominantly Black population it is charged to protect (e.g., Badger 2014). Clearly, the pronounced mismatch between racial demographics of the city's police force and the community at large is not unique to Ferguson (Ashkenas and Park 2015), and the underrepresentation of racial minorities has long been considered a central issue in policing. ${ }^{1}$

Black and, to a more limited extent, Hispanic representation in policing is a topic of interest in criminal justice and public administration scholarship (e.g., Gustafson 2013; Lewis, 1989; Kerr and Mladenka 1994; Regoli and Jerome 1975; Ramirez 1997; Saltzstein 1989; Stokes and Scott 1996; Zhao and Lovrich 1998, 2006; Zhao et al 2005; Zhao et al 2001). However, these studies have not incorporated important insights derived from other related bodies of research about factors that may strongly influence Black and Hispanic police hiring. Specifically, research on racial representation in policing regularly fails to incorporate theories of race relations and group threat (Blalock 1967; Blumer 1958), which has found that as a minority

\footnotetext{
${ }^{1}$ For example, minority underrepresentation within police departments was identified as a major issue in both the 1967 President's Commission on Law Enforcement and, under President Obama, the Administration of Justice and the President's Task Force on 21st Century Policing.
} 
population share increases, so too does the perceived competitive threat to the dominant majority population, who respond by using their privileged position to diminish the relative standing of minorities.

Although there is substantial debate over the precise mechanisms linking minority population concentration to various indicators of minority-majority inequality, the association between the relative concentration of a racial minority group in a given place (i.e. county, city, or metropolitan area) and a number of indicators of minority-majority inequality is one of the most widely cited findings in the social scientific study of racial inequality (e.g., Albrecht et al 2005; Cohen 1998, 2001; Cohen and Huffman 2007; Jaret et al 2003). This body of research has focused primarily on the effects of racial composition (typically Black or nonwhite) and both racial economic inequality (e.g., Albrecht et al 2005; Cohen 1998; Cohen and Huffman 2007; 2001; Huffman and Cohen 2004; Jaret et al 2003;Tienda and Lii 1987) and outcomes such as the size of the police force, police expenditures, and deadly use of police force (Eitle et al 2002; Jackson and Carroll 1981; Kent and Jacobs 2005; Legewie and Fagan 2016; Liska 1992; Stults and Baumer 2007). Recent research has found significant effects for racial composition and segregation on levels of crime control, particularly on police force size, as well as a positive relationship between officer involved killings of African Americans and factors commonly associated with group threat, including ethnic/racial polarization and Black-on-white homicides (Legewie and Fagan 2016). Interestingly, Legewie and Fagan (2016) found that proportional racial representation in police departments reduced the influence of minority threat effects, lowering the number of officer-involved killings of African Americans.

However, while there is a clear correlation between local area minority group size and the overall size of the police force in that area, and an empirical relationship between police force 
racial composition and the likelihood of officer-involved killings of African Americans, it is unclear whether patterns of minority representation in policing are consistent with the minority threat perspective such that racial minority underrepresentation in policing is positively associated with local level minority population share. Likewise, much remains unclear regarding how organizational attributes, such as department size and organizational leadership, may be associated with variation in racial representation in policing both within and between places. In this study we extend research on "minority threat" effects by examining how local level demographic dynamics are associated with Black/Hispanic representation in policing using confidential establishment-level data on police departments linked to local labor market population data. This study also extends research on organizational theory by evaluating whether department size may influence minority representation in policing and potentially mediate threat effects on minority underrepresentation in policing.

\section{The Racial Composition of Police Departments}

Recent high profile shootings of unarmed minorities by the police have enflamed tensions between minority communities and the law enforcement officers charged with their safety. Likewise, recent research has highlighted how police are a distinct social group with a unique collective identity and their own concerns about safety, legal protection, and public image (Holmes 2000; Smith and Holmes 2014). From this perspective, the perceived level of threat among officers is an important driver of group conflict based on the view of the police as in opposition to minority groups, particularly Blacks, which has been given voice by the emergence of "Blue Lives Matter” as a counter movement to "Black Lives Matter.” Indeed, recent research has shown that police may respond to perceived level of threat among officers in their 
interactions with Black citizens. For example, Legewie (2016) shows that violent attacks against police officers increase the subsequent use of police force against Blacks but not against other groups.

While animosity between Black citizens and the police appears to be reaching a fever pitch, social science research may suggest a tentative path forward. Although increasing diversity among the police workforce will not resolve all issues related to police-minority relations and the fairness and effectiveness of policing, increasing the number of Black and Hispanic officer provides opportunities for contact and interactions between officers from different racial and ethnic backgrounds and the experiences and insight from these interactions can increase familiarity and reduce stereotypes (Allport 1954; Pettigrew 1998) as well as potentially reducing hostility towards minority communities (Goldstein 1977; Smith 2003). Minority officers are perceived as more empathetic to minority concerns (Theobald and Haider-Markel 2008) which has important implications for police citizen interactions (Weitzer 2000). Likewise, the presence of Black and Hispanic police officers introduces different views that are aligned with and reflect minority interests (Sun and Payne 2004), and a government workforce that is demographically representative of the people it serves theoretically helps to ensure that the interests of all groups are considered in bureaucratic decision-making processes (Mosher 1968). This theory, referred to as "representative bureaucracy,” posits that individual civil servants are more likely to actively represent the interests of those who share their demographic backgrounds (see Bradbury and Kellough 2010 for a review). At the individual level, Black officers are less biased toward Black citizens (Antonovics and Knight 2009; Anwar and Fang 2006; Fagan et al 2016; Fagan and Geller 2010) and Black and Hispanic officers may exhibit less racial bias towards citizens of all races than their White counterparts (Close and Mason 2006, 2007; Gilliard et al 2008). 


\section{Determinants of Minority Representation in Police Departments}

Racial diversity in U.S. police agencies, particularly Black representation in policing, has a long tradition in criminal justice and public administration and has produced a consistent set of findings. Using the percentage of Black or Hispanic police officers at the department level as the primary dependent variable, this body of research finds that Black or Hispanic population share at the city or county level (the vast majority of these studies examine large municipal police departments) is the single strongest predictor of the proportion of African American officers on a police force (e.g., Lewis, 1989; Kerr and Mladenka; Saltzstein 1994; Zhao and Lovrich 1998, 2006; Zhao et al 2005; Zhao et al 2001). In addition to minority population share, the presence of a Black or Hispanic chief has also been identified as a strong predictor of increased hiring rates for members of their respective ethnic groups (Kerr and Mladenka 1994; Lewis 1989; Zhao et al 2005; Zhao and Lovrich 1998). However, research on labor market and stratification by scholars in sociology, economics, and other related fields, has shown that greater minority representation may mask increased relative underrepresentation (e.g., Cohen and Huffman 2007).

\section{Job Queues}

The incorporation of insights derived from queuing theory might help to explain the persistent finding that minority population share predicts the proportion of minorities employed in municipal police agencies. Queuing theory suggests that the ordering and composition of labor and job queues determine the matches between workers and jobs because employers select workers from the top of the labor queue, leaving workers who are at the bottom of the queue with the least desirable jobs. The composition of the available labor force and employers’ preferences regarding workers' characteristics play crucial roles in determining the structure of labor queues (Reskin 2001; Reskin and Ross 2009). Thus, even if minorities occupy a 
disadvantaged position in a police hiring que, minorities will likely be hired nonetheless if they compose a significant share of the available labor pool (Huffman and Cohen 2004). Any measure of minority representation that fails to account for the available labor pool is misleading because minorities may still be underrepresented even if they compose a significant proportion of the police force if minorities make up a greater proportion of the available labor pool. Past research on police forces has used a measure of minority representation that does not take the available labor pool into account, that is, relative underrepresentation

\section{Group Threat}

As previously mentioned, past research on racial diversity in police departments has largely failed to integrate insights from minority threat theory (but see Gustafson 2013). The threat hypothesis predicts that minority and majority group members compete with each other for economic and political resources and higher levels of minority group representation increase potential competition between groups, creating a perception of threat among majority group members (Blalock 1967). While most of this research has focused on Black population share, a few studies have focused on Hispanics (e.g. Saenz 1997; Tienda 1992). Black representation in a variety of geographic areas is positively associated with a number of adverse labor market and economic outcomes such as unemployment for Black youths (McCreary, England, and Farkas 1989) and Black-white occupational segregation (Huffman and Cohen 2004), and it is negatively associated with Black income (often relative to white income; Blalock 1957; Brown and Fuguitt 1972; Frisbie and Neidert 1977; Cassirer 1996; Beggs, Villemez, and Arnold 1997; Cohen 1998).

Research using establishment level data linked to local level population demographics suggests that threat effects also influence organizational hierarchies. For example, Cohen and Huffman (2007) found a positive association between the proportion African American in the 
local labor market and African American underrepresentation in management in the private sector. However, at the establishment level, Black workers were more likely to find themselves concentrated under the authority of non-representative management structures in labor markets with larger African American populations. Research on minority threat effects has consistently found a strong relationship between Black population share and police force size across geographic areas in the United States (Jacobs 1979; Jackson and Carroll 1981; Liska et al. 1981; Greenberg et al. 1985; Chamlin 1989; Brandl et al. 1995; Kane 2003; Kent and Jacobs 2005; Stults and Baumer 2007), but the issue of relative underrepresentation is less well understood.

\section{Department Size}

Establishment and organization size have been a focus for researchers interested in the organizational attributes that affect stratification-based aspects of work (e.g., Baron et al 1991; Bygren and Kumlin 2005). Organizational theorists have offered competing expectations for the effect of organizational size on ascription-based stratification in the workplace. Large organizational size can either inhibit or enable organizational change, in part because organizational size is seen as a proxy for a diverse set of organizational features such as bureaucratization, formalization, and visibility. The population ecology perspective suggests that larger organizational size will slow racial integration because large organizations rely on complex bureaucratic systems that are slow to change (Barron et al 1991). In contrast, scholarship on organizational legitimacy suggests that large size can decrease ascriptive inequality because of greater oversight by government regulators and visibility to the public, which can increase pressure to conform to societal expectations (Salancik 1979) and industry specific normative standards (Stainback and Tomaskovic-Devey 2012). Thus, in the context of policing, it is unclear whether larger police departments will exhibit more or less racial 
underrepresentation. Although size may increase bureaucratization and foster inertia, which might limit racial integration, larger departments also may be more susceptible to increased external pressures (public visibility, regulatory oversight, lawsuits) and internal pressures (administrative oversight and formalized personnel policies) that may be favorable to minority employment.

\section{Organizational Leadership}

A large body of research affirms the importance of organizational leadership for influencing ascriptive inequality in the workplace (e.g. Kalev et al 2006; Castilla 2011; Stainback and Kwon 2012; Kurtulus and Tomaskovic-Devey 2012). While this line of investigation is less developed with regards to race, a growing body of empirical research has shown that top female administrators can influence within-firm gender integration (Baron et al 1991), the occupational gender desegregation of non-managerial workers (Huffman,et al 2010; Stainback et al 2016), gender wage inequality (Cohen and Huffman 2007) (but see Srivastava and Sherman 2015), increases in the share of women in midlevel management positions (Kurtulus and Tomaskovic-Devey 2012; Skaggs et al 2012; ), and increases in the number of newly created jobs first filled by women (Cohen and Broschak 2013). Scholarship on policing has emphasized the importance of police chiefs for minority hiring, but it is likely that minorities in other high level administrative positions may also influence racial representation in hiring. While police chiefs frequently turnover, it is likely that minorities in high level administrative positions, such as hiring managers, may have longer tenures and greater overall influence on hiring patterns long term. Likewise, the overall proportion of high level administrators who are minorities may exert an indirect influence on hiring decisions by influencing department culture (Dulaney 1996). 


\section{Research Questions and Empirical Expectations}

In this study we use confidential establishment-level data on police departments linked to local labor market population data to examine how local level demographics are associated with Black/Hispanic representation in policing, and evaluate whether department size and the percent of Black/Hispanic top leadership positions may influence minority representation in policing, potentially mediating threat effects on minority underrepresentation. Based on the literature reviewed, we hypothesize that minority group size in the population (i.e. proportion Black and Hispanic) will be negatively associated with Black and Hispanic representation in local area police departments, relative to expected minority shares. However, we anticipate that department size the percent Black/Hispanic in leadership positions will be positively associated with Black and Hispanic representation in policing relative to the local area population, and will mediate minority threat effects.

\section{Data}

Data are derived from establishment level police employment records from U.S. Equal Employment Opportunity Commission’s (EEOC) EEO-4 survey for years 2007, 2009, and 2011, combined with metropolitan-area data on the racial composition of labor markets from the American Community Survey (ACS) 5-year file for 2007-2011. The EEO-4 survey is a mandatory government survey administered every odd year by EEOC to all U.S. municipalities, counties, townships, and state governments with more than 100 employees. We access the data through an Interagency Personnel Agreement with the EEOC; under this agreement, we may not disclose any results for identifiable police departments, and only report descriptions of geographic areas containing multiple departments. 
In their EEO-4 reports, these agencies must provide public employee counts on the gender and race/ethnic distribution of employees across major occupational groups, and functional policy areas (e.g., public welfare, police, fire, financial administration, etc.). These data allow us to examine the racial composition of police officers and top level administrators and officials ${ }^{2}$ for all police departments in the U.S. at the municipal and county level. To account for missing years of data we average counts for the total number of police officers, the total number of Hispanic and Black officers in each department, and the same counts for top-level administrators and officials, for the years 2007, 2009, and 2011.The ACS 5-year file for 20072011 is a 5 percent nationally representative sample of the U.S. population for the period 20072011. Thus, both files are centered on the year 2009.

We identified local labor markets using the Census defined metropolitan combined statistical areas (CSAs), which are defined by commuting patterns, and calculated total population counts for each CSA and population counts for non-Hispanic Blacks and Hispanics. Most studies which examine the determinants of racial representation in police departments examine large municipalities (e.g., Gustafson 2013; Lewis, 1989; Kerr and Mladenka 1994; Ramirez 1997; Saltzstein 1989; Zhao and Lovrich 1998; Zhao et al 2005) and employ municipal level population data to approximate the local labor market demographics. However, municipal population data does not usually correspond to actual commuter patterns and may provide a misleading indicator of labor market demographics as well as a misleading sense of the police service population (i.e. the population subject to regular interaction with local police). Due to high levels of residential segregation, the use of population data confined to city or county limits

\footnotetext{
2 These are occupations in which employees set broad policies, exercise overall responsibility for execution of these policies, or direct individual departments or special phases of the agency's operations, or provide specialized consultation on a regional, district or area basis. Includes: department heads, bureau chiefs, division chiefs, directors, deputy directors, controllers, police chiefs, and other.
} 
may mischaracterize actual local level demographic dynamics due to White flight or other race and class-based patterns of residential settlement, and may exclude a significant number of police jurisdictions on the periphery of municipalities. For example, the population of the city of Atlanta was 419,250 during the period under study and was approximately 54\% Black and 39\% Non-Hispanic White. However, the Atlanta metropolitan area, which includes adjacent counties and population centers with economic ties measured by commuting patterns, had a population of approximately 5,561,405 and was 31\% Black and 58\% Non-Hispanic White. In addition, while the City of Atlanta has one police department, the greater Atlanta metropolitan area and surrounding suburbs has 30 police departments with 50 or more officers and 19 departments with more than 100 hundred officers. Police departments, and other employers, are presumed to hire from the wider metropolitan area labor market rather than from the narrower jurisdictions they police.

\section{Sample, Measures, and Statistical Methods}

We limit our sample to departments that employ 50 police officers or more located within major labor markets ${ }^{3}$. We matched the demographic composition of police departments to the racial composition of the local labor market by (1) matching city or county names from the EEO4 file to Census geography names located within a Census designated commuter zone or CSA; and (2) extracting population counts from the Census Bureau’s American Community Survey. This generates a sample of 1,138 police departments. We differentiate large versus small departments at the cutoff of 250 officers.

\footnotetext{
${ }^{3}$ The department must be located within a combined metropolitan statistical area (CSA) as defined by the U.S. Census Bureau
} 
We use a binomial statistical test comparing within-department racial representation to the local labor market area racial composition. The test statistic is the discrepancy between the number of police officers who are of a given race (i.e. Black or Hispanic police officers) and the expected number of officers of that race given random selection from the population, divided by the standard deviation of the expected number. If this number is greater than 1.96 or less than 1.96, then we can conclude with $95 \%$ confidence the police were not selected at random from the population. This is a standard method used for comparing workforces to hiring pools (Cohen and Huffman 2007).

In the analysis we employ logistic regression using a dichotomous variable for Hispanic or Black police underrepresentation (i.e., departments with statistically significant underrepresentation of Black or Hispanic officers) as our dependent variable. Percent Black/Hispanic among the top administrators and officials, and the interaction of the natural log of department size with metro-area percent Black/Hispanic, are our primary independent variables.

\section{Descriptive Statistics and Preliminary Analysis Summary}

Table 1 shows descriptive statistics for department and CSA characteristics, illustrating the variation in racial representation and size. While most departments employ less than 200 officers, the largest departments employ several thousand. Likewise, while Black and Hispanics make up less than $10 \%$ of police officers in the majority of departments, a number of departments employ a majority of Black/Hispanics and some departments are almost entirely Hispanic/Black. CSAs also vary substantially in size and demographic makeup. While Blacks/Hispanics make up less than $10 \%$ of population in most labor markets, a few CSAs are 
majority Black/Hispanic. At the extremes you have CSAs like the Bend-Redmond-Prineville CSA in Oregon, where Blacks and Hispanic make up less 1\% of the population, and the McAllen-Edinburg CSA in Texas where Hispanics are more than 90\% of population.

We present our preliminary analysis in Figure 1 and Table 2. Figure 1 show Black/Hispanic underrepresentation relative to relevant labor market population, by department size. The results of Figure 1 show high levels of Black and Hispanic underrepresentation in policing, particularly for Hispanics. Seventy-five percent of large police departments, and 68 percent of smaller departments, show significant underrepresentation of Hispanic police officers relative to the local population. Racial underrepresentation is mitigated by department size only for Blacks, with large departments showing a lower prevalence of underrepresentation (55 percent versus 64 percent); in contrast, Hispanic underrepresentation is more prevalent in large departments.

Table 2 presents the results of the logistic regression models, estimated separately for Black and Hispanic underrepresentation. We find that each of our independent variables is statistically significant for both Blacks and Hispanics. As anticipated, police departments in labor markets with larger Black and Hispanic populations, are more likely to have an underrepresentation of Black and Hispanic officers relative to the local population, although the effect is much stronger for Black population. In addition, those with a greater number of officers on their force are more likely to report underrepresentation of Black and Hispanic officers, but the significant interaction between department size and racial composition suggests that the increase in odds of underrepresentation associated with minority population size is mitigated in larger departments - consistent with our hypothesis that the greater visibility of large departments in high-minority communities contributes to greater representation on police forces. 
Finally, consistent with the hypothesis that racial diversity in organizational leadership will contribute to minority hiring, Black/Hispanic presence among top administrators and officials is significantly and negatively associated with Black/Hispanic underrepresentation among officers. Thus, racial diversity in organizational leadership may increase the probability that minorities are represented on police forces in proportion to their local population share.

\section{Discussion and Next Steps}

This is the first such paper on the determinants of racial representation in policing to incorporate research from the sociology of organizations and sociological theories of minority threat on police employment outcomes. We find evidence of connection between Black/Hispanic population size and racial minority underrepresentation in police departments, consistent with the group size/threat theory. However, that appears to be partially mitigated by department size and racial diversity in positions of organizational leadership, which is consistent with the idea that larger organizations are more vulnerable to political or legal pressure to hire representatively. This may be especially important among police forces, where (as in the case of Ferguson, Missouri), Black underrepresentation is especially pronounced where police departments are not large.

This analysis is preliminary, and we are pursuing additional research to move toward a stronger causal analysis. Specifically, the EEO-4 data is available for years 1973-2013, which will allow us to extend this analysis longitudinally. And the dataset also includes separate information on new hires each year. This will provide fertile ground for evaluating our theses with a longitudinal research design, which we expect to complete before August. 
Figure 1. Black/Hispanic underrepresentation relative to labor market population (percent of departments)

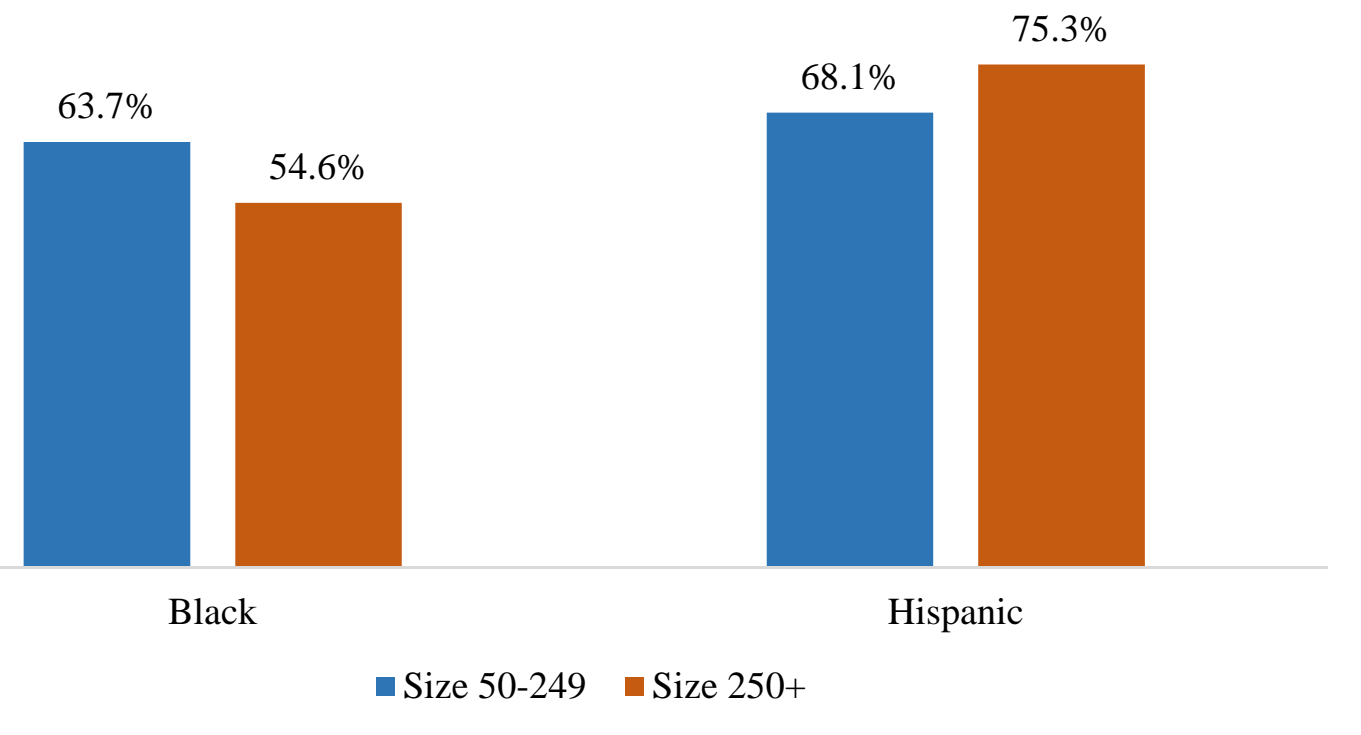

Table 1. Descriptive Statistics: EE04 Police Departments: 2007-2011

\begin{tabular}{lcccccc}
\hline Department Characteristics & 25th Per. & Median & 75th Per. & 90th Per. & Smallest & Largest \\
\hline Department Size & 88 & 126 & 242 & 525 & 50 & 37,271 \\
Percent Officers Black & $2 \%$ & $5 \%$ & $12 \%$ & $22 \%$ & $0 \%$ & $90 \%$ \\
Percent Officers Hispanic & $1 \%$ & $4 \%$ & $11 \%$ & $23 \%$ & $0 \%$ & $99 \%$ \\
& & & & & & \\
CSA Characteristics & 245,625 & 599,376 & $1,359,845$ & $3,161,317$ & 109,004 & $23,200,000$ \\
CSA Size & $3.1 \%$ & $6.9 \%$ & $14.5 \%$ & $26.9 \%$ & $0.3 \%$ & $47.7 \%$ \\
Percent Black & $12 \%$ & $6 \%$ & $4 \%$ & $35 \%$ & $1 \%$ & $91 \%$ \\
Percent Hispanic & & & & & &
\end{tabular}

Per. denotes percentile. $\mathrm{N}=1,138$. 
Table 2. Logistic regression coefficients for odds of Black/Hispanic underrepresentation: EE04 Police Departments: 2007-2011

\begin{tabular}{|c|c|c|c|c|}
\hline & \multicolumn{2}{|c|}{ Hispanic } & \multicolumn{2}{|c|}{ Black } \\
\hline Labor market percent Black/Hispanic & .12 & $* * *$ & .44 & $* * *$ \\
\hline Top Admin. percent Black/Hispanic & -4.03 & $* * *$ & -4.24 & $* * *$ \\
\hline Dept. Size (ln) & .45 & $* * *$ & .65 & $* * *$ \\
\hline Dep. percent Black/Hispanic * Dept. Size (ln) & -.01 & $*$ & -.06 & $* * *$ \\
\hline Constant & -2.13 & & -4.24 & $* * *$ \\
\hline Pseudo R2 & .08 & & .21 & \\
\hline
\end{tabular}




\section{References}

Albrecht, D.E., Albrecht, C.M. \& Murguia, E. 2005, "Minority concentration, disadvantage, and inequality in the nonmetropolitan United States", The Sociological Quarterly, vol. 46, no. 3, pp. 503-523.

Allport, G.W. 1979, The nature of prejudice, Basic books.

Antonovics, K. \& Knight, B.G. 2009, "A new look at racial profiling: Evidence from the Boston Police Department", The review of economics and statistics, vol. 91, no. 1, pp. 163-177.

Ashkenas, J. \& Park, H. 2015, "The race gap in America’s police departments", The New York Times, .

Baron, J.N., Mittman, B.S. \& Newman, A.E. 1991, "Targets of opportunity: Organizational and environmental determinants of gender integration within the California civil service, 19791985", American Journal of Sociology, , pp. 1362-1401.

Blalock, H.M. 1967, "Toward a theory of minority-group relations", .

Blumer, H. 1998, "Race prejudice as a sense of group position" in New Tribalisms Springer, , pp. 31-40.

Bradbury, M. \& Kellough, J.E. 2010, "Representative bureaucracy: Assessing the evidence on active representation", The American Review of Public Administration, .

Bygren, M. \& Kumlin, J. 2005, "Mechanisms of Organizational Sex Segregation Organizational Characteristics and the Sex of Newly Recruited Employees", Work and Occupations, vol. 32, no. 1, pp. 39-65.

Close, B.R. \& Mason, P.L. 2006, "After the traffic stops: Officer characteristics and enforcement actions", Topics in Economic Analysis \& Policy, vol. 6, no. 1.

Close, B.R. \& Mason, P.L. 2006, "After the traffic stops: Officer characteristics and enforcement actions", Topics in Economic Analysis \& Policy, vol. 6, no. 1.

Cohen, P.N. 2001, "Race, class, and labor markets: The white working class and racial composition of US metropolitan areas", Social science research, vol. 30, no. 1, pp. 146-169.

Cohen, P.N. 1998, "Black concentration effects on black-white and gender inequality: Multilevel analysis for US metropolitan areas", Social Forces, vol. 77, no. 1, pp. 207-229. 
Cohen, P.N. \& Huffman, M.L. 2007, "Black under-representation in management across US labor markets", The Annals of the American Academy of Political and Social Science, vol. 609, no. 1, pp. 181-199.

Dulaney, W.M. 1996, Black police in America, Indiana University Press.

Fagan, J., Braga, A.A., Brunson, R.K. \& Pattavina, A. 2015, "Stops and Stares: Street Stops, Surveillance and Race in the New Policing", Columbia Public Law Research Paper, , no. 14-479.

Gay, C. 2002, "Spirals of trust? The effect of descriptive representation on the relationship between citizens and their government", American Journal of Political Science, , pp. 717732.

Gustafson, J. 2013, "Diversity in municipal police agencies: A national examination of minority hiring and promotion", Policing: An International Journal of Police Strategies \& Management, vol. 36, no. 4, pp. 719-736.

Huffman, M.L. \& Cohen, P.N. 2004, "Racial Wage Inequality: Job Segregation and Devaluation across US Labor Markets1", American Journal of Sociology, vol. 109, no. 4, pp. 902-936.

Jackson, P.I. \& Carroll, L. 1981, "Race and the war on crime: The sociopolitical determinants of municipal police expenditures in 90 non-southern US cities", American Sociological Review, , pp. 290-305.

Jaret, C., Williams Reid, L. \& Adelman, R.M. 2003, "Black-White Income Inequality and Metropolitan Socioeconomic Structure", Journal of Urban Affairs, vol. 25, no. 3, pp. 305334.

Kent, S.L. \& Jacobs, D. 2005, "Minority threat and police strength from 1980 to 2000: A fixedeffects analysis of nonlinear and interactive effects in large US cities", Criminology, vol. 43, no. 3, pp. 731-760.

Kerr, B. \& Mladenka, K.R. 1994, "Does politics matter? A time-series analysis of minority employment patterns", American Journal of Political Science, , pp. 918-943.

Lewis, W.G. 1989, "Toward representative bureaucracy: Blacks in city police organizations, 1975-1985", Public administration review, , pp. 257-268.

Liska, A.E. 1992, Social threat and social control, Suny Press.

Mosher, F.C. 1968, Democracy and the public service, New York.

Pettigrew, T.F. 1998, "Reactions toward the new minorities of Western Europe", Annual review of sociology, , pp. 77-103. 
Ramirez, E.J. 1997, Hispanic policing in local government, .

Reskin, B.F. 2001, "Labor markets as queues: a structural approach to changing occupational sex composition", American Sociological Review, vol. 52, no. 2, pp. 195-210.

Reskin, B.F. \& Roos, P.A. 2009, Job queues, gender queues: Explaining women's inroads into male occupations, Temple University Press.

Saltzstein, G.H. 1989, "Black mayors and police policies", The journal of Politics, vol. 51, no. 03, pp. 525-544.

Stainback, K. \& Tomaskovic-Devey, D. 2012, Documenting desegregation: Racial and gender segregation in private sector employment since the Civil Rights Act, Russell Sage Foundation.

Stokes, L.D. \& Scott, J.F. 1996, "Affirmative action and selected minority groups in law enforcement", Journal of Criminal Justice, vol. 24, no. 1, pp. 29-38.

Stults, B.J. \& Baumer, E.P. 2007, "Racial Context and Police Force Size: Evaluating the Empirical Validity of the Minority Threat Perspective1", American Journal of Sociology, vol. 113, no. 2, pp. 507-546.

Theobald, N.A. \& Haider-Markel, D.P. 2009, "Race, bureaucracy, and symbolic representation: Interactions between citizens and police", Journal of Public Administration Research and Theory, vol. 19, no. 2, pp. 409-426.

Tienda, M. \& Lii, D. 1987, "Minority concentration and earnings inequality: Blacks, Hispanics, and Asians compared", American journal of sociology, , pp. 141-165.

Zhao, J., Herbst, L. \& Lovrich, N. 2001, "Environmental and institutional effects present in the employment of women police officers: Separating the predictors of minority and nonminority female officer hiring", Journal of Urban Affairs, vol. 23, pp. 243-257.

Zhao, J.“., He, N. \& Lovrich, N.P. 2006, "Pursuing gender diversity in police organizations in the 1990s: A longitudinal analysis of factors associated with the hiring of female officers", Police Quarterly, vol. 9, no. 4, pp. 463-485.

Zhao, J. \& Lovrich, N. 1998, "Determinants of minority employment in American municipal police agencies: The representation of African American officers", Journal of Criminal Justice, vol. 26, no. 4, pp. 267-277. 